\title{
Influence of Nitrogen Ion Implantation on the Disc Brake Material of Motor Vehicles Component
}

\author{
Bangun Pribadi $^{1}$, Emy Mulyani ${ }^{2, *}$, Tjipto Sujitno ${ }^{2}$ \\ ${ }^{1}$ Electromechanical Department, Polytechnic Institute of Nuclear Technology, Yogyakarta, Indonesia \\ ${ }^{2}$ Particle Physics Department, Center for Accelerator Science and Technology, Yogyakarta, Indonesia \\ Email address: \\ bangunpribadisttn@gmail.com (B. Pribadi), emymulya@batan.go.id (E. Mulyani), tjiptosujitno@batan.go.id (T. Sujitno) \\ ${ }^{*}$ Corresponding author
}

\section{To cite this article:}

Bangun Pribadi, Emy Mulyani, Tjipto Sujitno. Influence of Nitrogen Ion Implantation on the Disc Brake Material of Motor Vehicles Component. Advances in Materials. Vol. 8, No. 3, 2019, pp. 132-136. doi: 10.11648/j.am.20190803.16

Received: July 22, 2019; Accepted: September 16, 2019; Published: September 29, 2019

\begin{abstract}
Weaknesses of local disc brakes are cover several conditions such as low hardness, wear, and corrosion resistance. To improve this weakness, it is necessary to modify the surface properties of the material. The aim of this research is to study the influences of nitrogen ion implantation on the surface properties of a disc brake material. The implantation process was carried out for various of ions dose such as $3.107 \times 10^{16}$ ions $/ \mathrm{cm}^{2}, 3.148 \times 10^{16}$ ions $/ \mathrm{cm}^{2}, 3.728 \times 10^{16}$ ions $/ \mathrm{cm}^{2}, 4.039 \times 10^{16}$ ions $/ \mathrm{cm}^{2}$, $4.350 \times 10^{16} \mathrm{ions} / \mathrm{cm}^{2}$ at a certain energy and beam current of $60 \times 10^{16} \mathrm{ions} / \mathrm{cm}^{2}, 30 \mu$ A respectively. Hardness and wear properties were tested using microhardness tester and wear testing machine, respectively. Meanwhile, the crystalline structure for un-implanted (raw) and implanted materials at the optimum dose was analyzed using XRD. From the hardness test results, it can be obtained that the hardness of raw material is $59.82 \mathrm{VHN}$ and after implantation it reached the highest value of $109.78 \mathrm{VHN}$ or increases by factor $83 \%$, while the wear test results is $22.9 \times 10^{-9} \mathrm{~mm}^{2} / \mathrm{kg}$ for raw material and after implantation it reaches the highest value of $2.5 \times 10^{-9} \mathrm{~cm}^{2} / \mathrm{kg}$ or decreases by factor $88 \%$. These conditions were obtained at $3.728 \times 10^{16}$ ions $/ \mathrm{cm}^{2}$ of dose. Based on the XRD analysis, $45.5 \% \mathrm{Fe}_{2} \mathrm{~N}$ and $54.55 \% \mathrm{Fe}_{3} \mathrm{~N}$ compounds are formed.
\end{abstract}

Keywords: Ion Implantation, Disc Brake, Hardness Test, Wear Test, XRD

\section{Introduction}

A braking system is one of the critical safety components of an automobile. It is mainly used to decelerate vehicles from an actual speed to the desired speed. Friction based braking systems are still a conventional device to convert kinetic energy into thermal energy, through friction between the brake pads and the rotor faces [1-4]. All braking system depends upon the frictional force to stop, control or prevent motion [5, $6]$. Because these components are always rubbing against the surface of other components, it will wear out quickly so that their service life will also be reduced. To reduce the wear rate or to extend the fatigue life or service life, the surface of the component needs to be improved. Several surface treatment methods are used to improve the surface quality such as carburizing, nitriding, carbonitriding, induction hardening, shot peening, physical vapor deposition (PVD) and chemical vapor deposition (CVD), as well as an ion implantation technique $[7,8]$. These treatments form a hardened surface layer with compressive residual stress, and therefore, the fatigue life is improved by the surface layer $[9,10]$.

Ion implantation is a surface modification technique by which atoms and molecules are ionized, accelerated in an electrostatic field, and implanted into the near-surface of a substrate. This technique produces a modification in the structure of metals by the formation of new crystalline phases, metastable or amorphous, and thus to improve the surface properties [11]. A great advantage is the negligible effect of ion implantation on the dimensions of the treated element; hence, the process can be applied in the final stage of manufacturing of products that already have their final dimensions [12]. Besides the improvement of tribological properties, ion implantation contributes to an increase in mechanical strength. This is associated with an increase in the microhardness of the implanted samples. The implantation process is accompanied with the appearance of compressive stresses and inclusions of nitrides, carbides, and borides. The 
implantation-induced hardening process depends on the type and dose of implanted ions and the temperature of the implanted material. In most of the applications for surface treatment, implanted elements are nitrogen, carbon and boron that harden the surface alloy as a consequence of fine particle formation by precipitation. The introduction of new atoms in the crystal lattice is not the only effect of ion implantation, but also the damage originated in the crystal structure of the target by the energetic collision cascades must also be taken into account [13]. As each ion penetrates the target, it undergoes a series of collisions displacing host atoms along the way. Both the ion and dislodged target atoms can continue and cause further damage, and so the energy is spread over many moving particles. Therefore, after implantation of high doses of ions, an initially crystalline target will be so perturbed that it will have changed to a highly disordered state [14]. The amount of crystallographic damage can be enough to cause the partial amorphization of the metal surface, depending on the dose, energy, temperature (governing self-annealing that can occur to repair some or all of the damage as it is generated) and ion species (heavy ions displace a greater volume of target atoms per ion) [15]. Finally, the implantation of a high dose of ions induces significant compressive stress that can contribute to the blocking of the fissures and close the channels of corrosion [16].

\section{Methodology}

The material that is used in this study was a local disc material, the type of component is presented in Figure 1. In this experiment, local disc component was cut into specimens $4 \times 14 \mathrm{~mm}$ in size in a disc shape using a wather jet cutting. The specimens were grounded with $\mathrm{SiC}$ papers from 80 up to 5000 mesh and polished mechanically with $1 \mu \mathrm{m}$ diamond paste. The polished specimens were washed with acetone in an ultrasonic cleaner and dried at room temperature. The chemical compositions of the samples are listed in Table 1. The samples were implanted by using $150 \mathrm{keV} / 2 \mathrm{~mA}$ ion implanter. Implantation of the samples performed at dose $3.107 \times 10^{16} \mathrm{ion} / \mathrm{cm}^{2}, 3.148 \times 10^{16} \mathrm{ion} / \mathrm{cm}^{2}, 3.728 \times 10^{16} \mathrm{ion} / \mathrm{cm}^{2}$, $4.039 \times 10^{16} \mathrm{ion} / \mathrm{cm}^{2}$ and $4.35 \times 10^{16}$ ion $/ \mathrm{cm}^{2}$ at $60 \mathrm{keV}$ of ions energy. The increase of the temperature of the samples was ensured solely by the incoming ion beam without any additional heating.

Table 1. Chemical Composition of local disc brake.

\begin{tabular}{ll}
\hline Element & Quantity (\%) \\
\hline $\mathrm{C}$ & 0.0720 \\
$\mathrm{Si}$ & 0.0606 \\
$\mathrm{P}$ & 0.0041 \\
$\mathrm{Mn}$ & 1.7266 \\
$\mathrm{Ni}$ & 0.0113 \\
$\mathrm{Cr}$ & 0.0252 \\
$\mathrm{Mo}$ & 0.0073 \\
$\mathrm{Cu}$ & 0.0121 \\
$\mathrm{Ti}$ & 0.0446 \\
$\mathrm{Sn}$ & 0.0011 \\
\hline
\end{tabular}

\begin{tabular}{ll}
\hline Element & Quantity (\%) \\
\hline $\mathrm{Al}$ & 0.0464 \\
$\mathrm{Nb}$ & 0.0522 \\
$\mathrm{~V}$ & 0.0062 \\
$\mathrm{Co}$ & 0.0020 \\
$\mathrm{~Pb}$ & 0.0064 \\
$\mathrm{Ca}$ & 0.0056 \\
$\mathrm{Zn}$ & 0.0100 \\
$\mathrm{Fe}$ & 97.9 \\
\hline
\end{tabular}

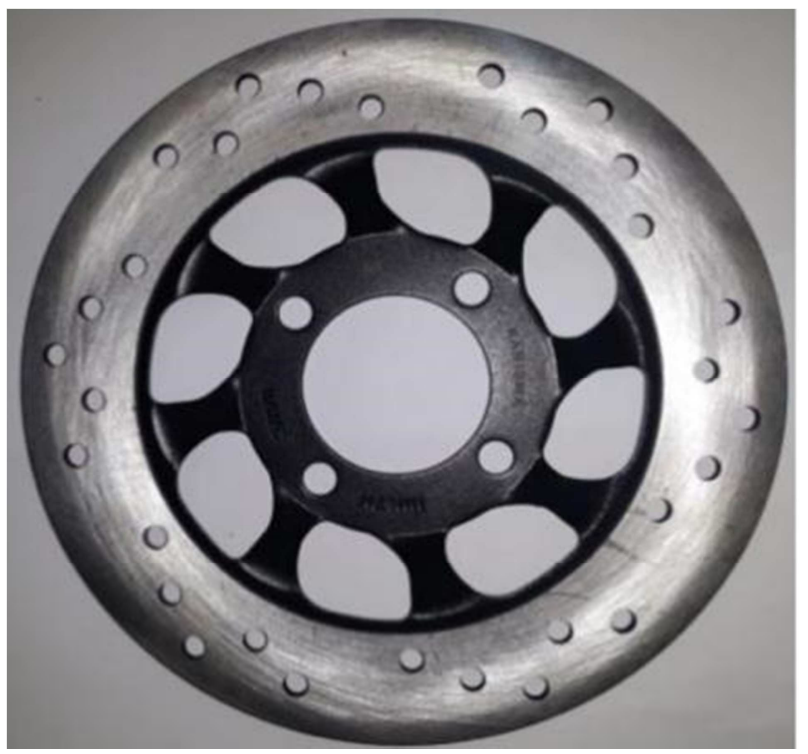

Figure 1. A type of local disc component.

\section{Result and Discussion}

\subsection{Analysis of the Hardness and Wear Rate}

The effect of nitrogen ion implantation in micro-hardness properties of samples was tested by using Vickerss Tester Microhardness Tester type MTX7, while the wear properties were tested using the Ogoshi High Speed Universal Wear Testing Machine with the result as shown in Figure 2. It concluded that the hardness and wear rate of samples improved after nitrogen ion implantation and extend of improvement increases with the dose. The maximum hardness is appearing at a nitrogen ion dose of $3.728 \times 10^{16} \mathrm{ion} / \mathrm{cm}^{2}$. In this condition, the hardness increase from 59.77 VHN (raw material) to $109.78 \mathrm{VHN}(83 \%$ higher $)$, while the wear rate decreases from dose $3.107 \times 10^{16} \mathrm{ion} / \mathrm{cm}^{2}$ to $3.728 \times 10^{16}$ ion $/ \mathrm{cm}^{2}$ or reduce by a factor $88 \%$. Over this dose the hardness decreases while the wear rate increases. This may be caused by defects due to the excess nitrogen ions implantations.

Table 2. Peaks positions and interplanar spacings for un-implanted local disc brake materials.

\begin{tabular}{llll}
\hline $\mathbf{2 \Theta}$ (degree) & d-spacing $(\AA)$ & Intensity & hkl \\
\hline 44.67 & 2.0271 & 10.00 & 101 \\
64.91 & 1.4354 & 39.57 & 200 \\
82.25 & 1.1712 & 130.47 & 211 \\
98.72 & 1.0066 & 52.16 & 202 \\
\hline
\end{tabular}




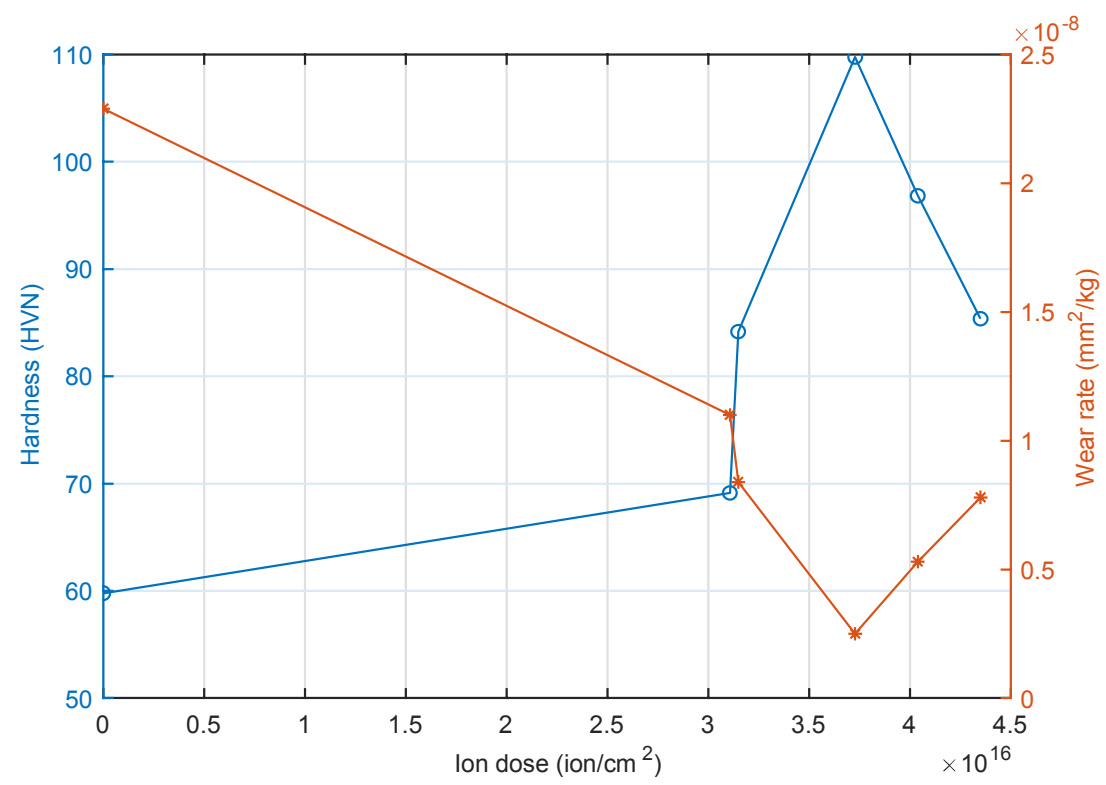

Figure 2. Effect of nitrogen dose on the hardness and wear rate of implanted samples (local disc material).

\subsection{XRD Analysis of Implanted and Un-implanted Samples}

The phase composition of nitrogen- implanted samples was analyzed using X-rays in the $\Theta-2 \Theta$ mode and $\lambda=1.548 \AA$ of $\mathrm{CuK} \alpha$ radiation. The presence of nitride in implanted samples at optimum conditions was revealed by the spectrum in Figure 4, Tables 3, and 4. Figure 3 and Table 2 show the XRD patterns of un-implanted sample material.

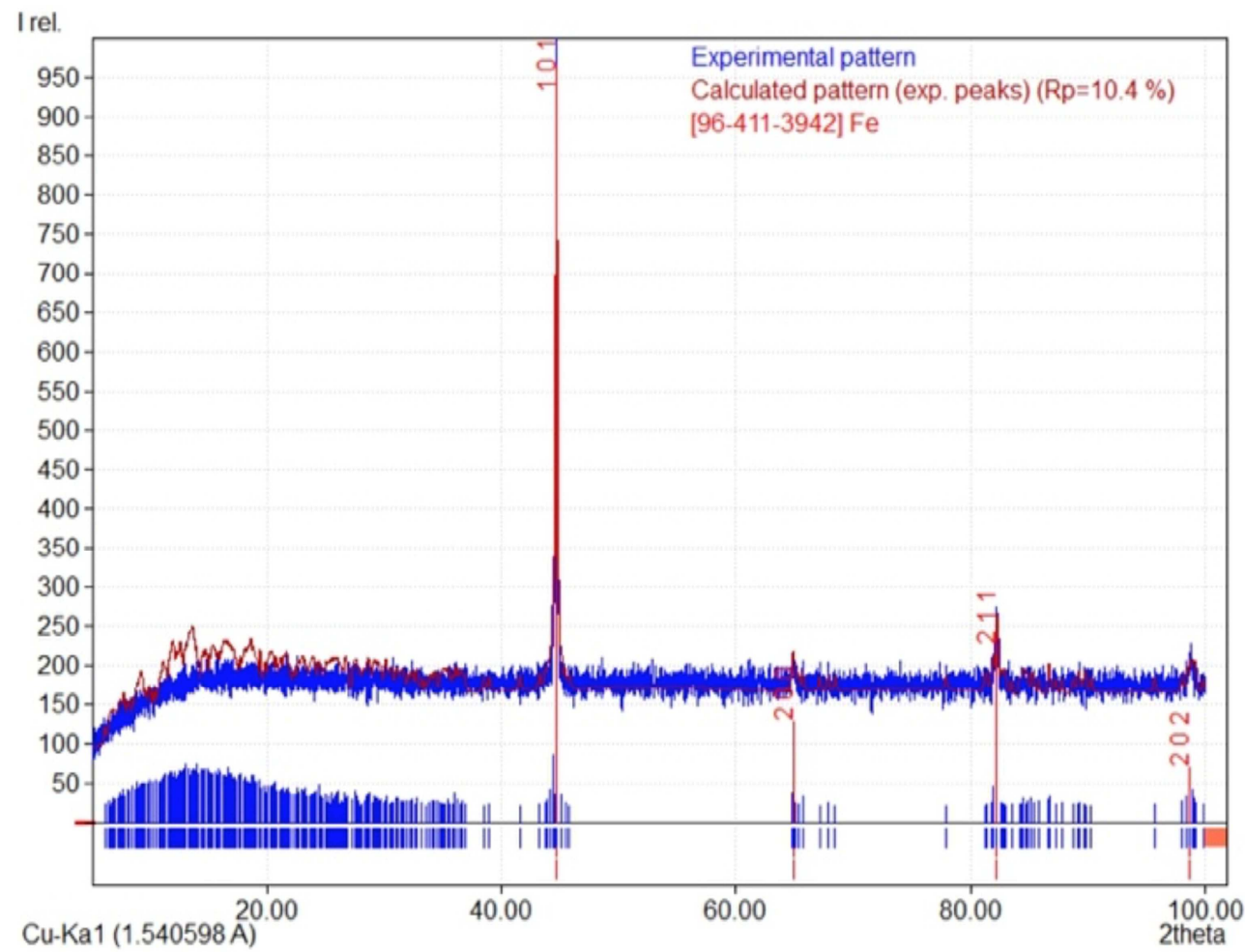

Figure 3. X-ray pattern of the un-implanted local disc samples materials.

The pattern in Figure 3 (un-implanted material) shown (101), (200), (211), and (202) peaks with cubic structures at $2 \Theta=44.67^{\circ}, 64.91^{\circ}, 82.25^{\circ}$, and $98.72^{\circ}$ respectively. Those peaks are related to the low alloys steel substrate with iron $(\mathrm{Fe})$ as the main element. A Crystallography Open Database
(COD), entry number 96-411-3942 code show that the phase is $\alpha \mathrm{Fe}$ (alpha-iron). The XRD pattern for implanted material with nitrogen ions at $3.728 \times 10^{16} \mathrm{ion} / \mathrm{cm}^{2}$ of ions dose is shown in Figure 4. A COD, entry number 96-411-3942 code show that the phases are $54.5 \%$ of $\mathrm{Fe}_{3} \mathrm{~N}$ and $45.5 \%$ of $\mathrm{Fe}_{2} \mathrm{~N}$. 


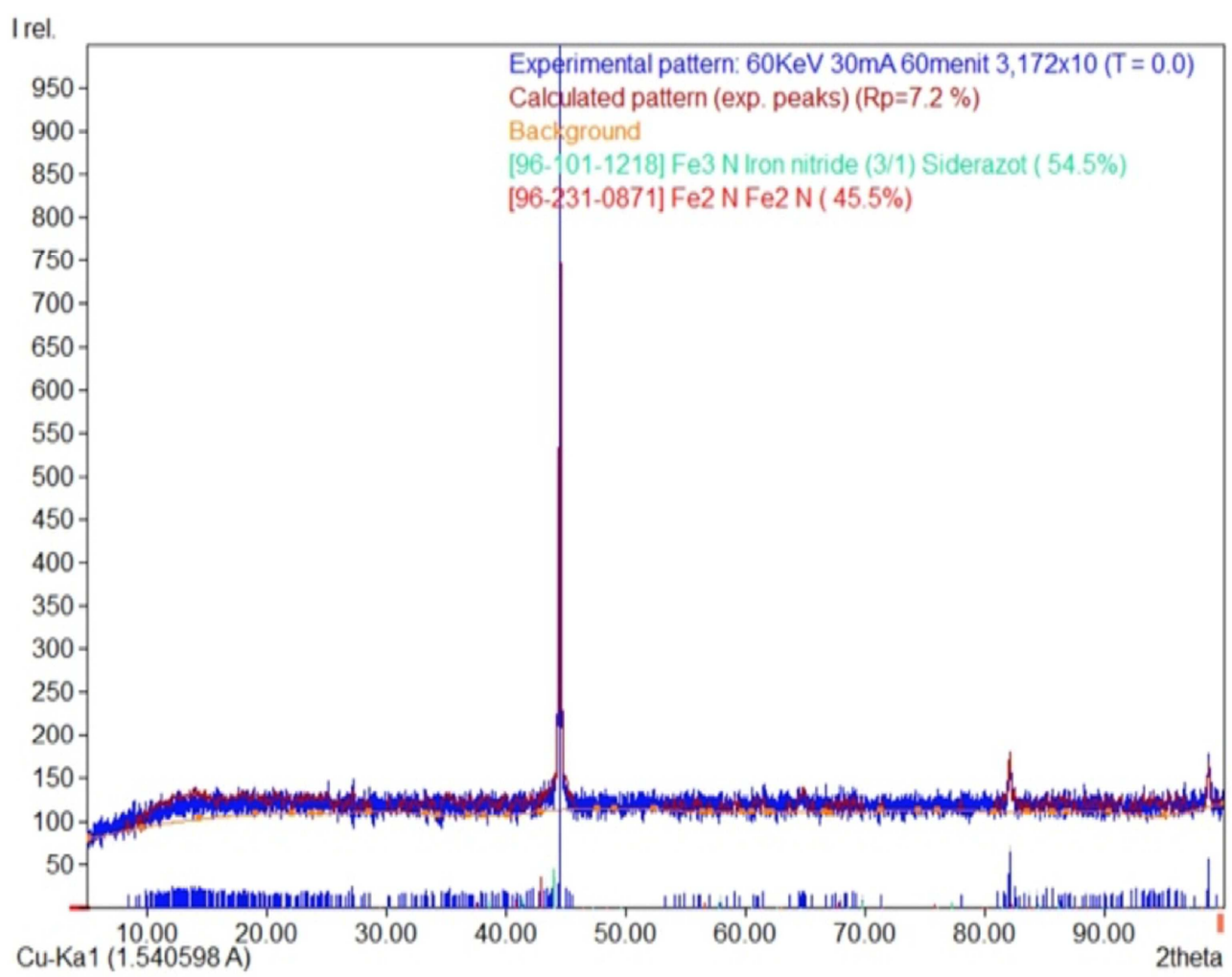

Figure 4. XRD pattern of implanted samples with nitrogen ions at energy of $60 \mathrm{keV}$ for 60 minutes of implantation time or $3.728 \times 10^{16}$ ion $/ \mathrm{cm}^{2}$ of ions dose $(45.5 \%$ of $\mathrm{Fe}_{2} \mathrm{~N}$ phase and $55.5 \%$ of $\mathrm{Fe}_{3} \mathrm{~N}$ phase).

Table 3. $\mathrm{Fe}_{2} \mathrm{~N}$ phase peaks positions and interplanar spacings for local disc brake materials.

\begin{tabular}{lllll}
\hline $\mathbf{2} \Theta($ graph $)$ & $\mathbf{2 \Theta}($ cal $)$ & d-spacing $(\AA)$ & Intensity & hkl \\
\hline 20.07 & 19.57 & 4.4101 & 15.77 & 001 \\
37.60 & 37.44 & 2.3851 & 14.64 & 11 \\
40.74 & 40.72 & 2.2081 & 19.34 & 002 \\
42.93 & 42.81 & 2.1027 & 21.60 & 111 \\
67.76 & 67.68 & 1.3802 & 16.59 & 300 \\
82.20 & 82.14 & 1.1730 & 72.34 & 302 \\
83.65 & 83.51 & 1.1549 & 18.94 & 221 \\
88.39 & 88.21 & 1.1054 & 19.04 & 004 \\
94.10 & 93.94 & 1.0527 & 23.85 & 222 \\
\hline
\end{tabular}

Table 4. $\mathrm{Fe}_{3} \mathrm{~N}$ phase peaks positions and interplanar spacings for local disc brake materials.

\begin{tabular}{lllll}
\hline $\mathbf{2 \Theta}($ graph) & $\mathbf{2 \Theta ( c a l )}$ & d-spacing $(\AA)$ & Intensity & hkl \\
\hline 21.97 & 21.9 & 4.0566 & 16.64 & 100 \\
30.11 & 30.04 & 2.9629 & 17.42 & 101 \\
38.54 & 38.52 & 2.3335 & 17.95 & 110 \\
41.35 & 41.34 & 2.1722 & 16.24 & 002 \\
43.96 & 43.92 & 2.0535 & 35.37 & 111 \\
57.81 & 57.88 & 1.5904 & 14.94 & 112 \\
64.57 & 64.54 & 1.4413 & 16.40 & 211 \\
69.73 & 69.97 & 1.3484 & 16.13 & 300 \\
82.61 & 82.59 & 1.1673 & 14.43 & 220 \\
84.43 & 84.22 & 1.1475 & 20.64 & 302 \\
86.20 & 86.62 & 1.1267 & 14.28 & 221 \\
\hline
\end{tabular}

\section{Conclusion}

Based on the experiments, it can be concluded as follow:

1. The hardness of un-implanted materials is $59.77 \mathrm{VHN}$, after being implanted for various of time or ions dose the hardness increased and reached optimum in order of $109.78 \mathrm{VHN}$ or increase by factor $83 \%$, while the wear rate decreased from $22.9 \times 10^{-9} \mathrm{~mm}^{2} / \mathrm{kg}$ to be minimum in order $2.5 \times 10^{-9} \mathrm{~mm}^{2} / \mathrm{kg}$ or decreased by factor $88 \%$. This optimum condition was achieved at 60 minutes of implantation time or at $3.728 \times 10^{16}$ ions $/ \mathrm{cm}^{2}$ of ions dose.

2. Based on XRD analysis and after being analyzed using Crystallography Open Database (COD) code entry number 96-411-3942 it's observed that for un-implanted samples the observed phase is $\alpha \mathrm{Fe}$, after being implanted at optimum conditions the formed phases are $54.5 \%$ of $\mathrm{Fe}_{3} \mathrm{~N}$ and $45.5 \%$ of $\mathrm{Fe}_{2} \mathrm{~N}$. The formation of these phases are causing in increasing the hardness or reducing the wear rate.

\section{Acknowledgements}

The authors gratefully acknowledge the financial support for this work from the Centre Accelerator Science and Technology, National Nuclear Energy Agency of Indonesia (CAST BATAN) as well as Mr. Ahmad Zainuri, Agus Wijayanto and Mrs Vika Arwida for their assistance during this research.

\section{References}

[1] Suprapto, Tjipto Sujitno, Ihwanul Aziz, Wiwien Andriyanti, Bangun Pribadi, Emy Mulyani, 2018, Effect of Post Treatment in Argon Environment of Plasma Nitrided Local Disc Brake. Advances in Materials. Vol. 8, No. 1, 2019, pp. 27-32. doi: 10.11648/j.am.20190801.14. 
[2] Daanvir Karan Dhir, Thermo mechanical performance of automotive disc brakes, 2018, Materials Today: Proceedings 5, 1864-1871.

[3] Qifei Jian, Yan Shui, 2017, Numerical and experimental analysis of transient temperature field of ventilated disc brake under the condition of hard braking, International Journal of Thermal Sciences 122, 115-123.

[4] S. C. Wu, S. Q. Zhang, Z. W. Xu, 2016, Thermal crack growth-based fatigue life prediction due to braking for a high-speed railway brake disc, International Journal of Fatigue 87 (2016) 359-369.

[5] Alnqi, AA Kosaleh, S, 2018, Material characterization of lightweight disc brake rotors, Journal of materials design and applications 232 (7).

[6] Aman Sharma, Prakhar Amrute, Suryakant Singh Thakur, Jatin Shrivastav, Design, analysis and fabrication of braking system with rear inboard brakes baja ATV, International Research Journal of Engineering and Technology (IRJET), Volume: 05 Issue: 05 May 2019.

[7] Behzad Fotovvati, Navid Namdari and Amir Dehghanghadikolaei,"On Coating Techniques for Surface Protection: A Review, Journal of Manufacturing and Materials Processing, 2019, 3, 28.

[8] Amir Dehghanghadikolaei 1 and Behzad Fotovvati 2, Coating Techniques for Functional Enhancement of Metal Implants for Bone Replacement: A Review, Materials 2019, 12, 1795.

[9] Jie Jin, Wei Wang and Xinchun Chen, Microstructure and Mechanical Properties of $\mathrm{Ti}^{+}$NIon Implanted Cronidur 30 SteeL, Materials 2019, 12, 427.
[10] Daesuke Yonekura, K. R. Sibahara, Insup Lee and R. Murakami, 2013, Very High Cycle Fatigue Behavior of Plasma nitrided 316 Stainless Steel, 13th International conference on fracture, June 16-21, Beijing China.

[11] R. Figueroa, C. M. Abreu, M. J. Cristóbal, G. Pena, 2012, Effect of nitrogen and molybdenumion implantation in the tribological behavior of AA7075 aluminum alloy, Wear 276$277,53-60$.

[12] P Budzyskietal 2016. The influence of nitrogen ion implantation on microhardness of the Stellite 6 alloy IOP Conf. Ser.: Mater. Sci. Eng. 148012046.

[13] Muhammad Shahnawaz, S Bashir, Muhammad Ahsan Shafique and Hussain, 2018, Study the effects of nitrogen ion implantation on structural and mechanical properties of AA7075, Materials Research Express, Volume 5 Number 7, Published 4 July 2018 C 2018 IOP Publishing Ltd.

[14] M. Manouchehrian, M. M. Larijani and B. Banagar 2014, Influence of Energy Nitrogen Ion Implantation on Structural and Mechanical Properties of Chromium Thin Film, J. Thin Fil. Sci. Tec. 3, No. 2, 67-70.

[15] K. Takeda A, K. Mitsui, H. Tobushi, N. Levintant-Zayonts, S. Kucharski, 2013, Influence of nitrogen ion implantation on deformation and fatigue properties of TiNi shape memory alloy wire, Arch. Mech., 65, 5, pp. 391-405, Warszawa.

[16] J. Wood, Gautam Majumdar, 2016 Ion Implantation, in Reference Module in Materials Science and Materials Engineering. 